\title{
A Study of Labour Welfare Measures in Co-Operative Sugar Mills of Haryana \\ ${ }^{1}$ MrKrishan Kumar ${ }^{2}$ Professor Darshan Singh Department of Social Work, Kurukshetra University, Kurukshetra
}

\begin{abstract}
In the industrial production of the country, employees play a significant role. Organizations must therefore secure employee cooperation so that production increases and higher benefits are achieved. Employees will be satisfied if they receive a sufficient amount of welfare services because it develops a sense of deep satisfaction for the management. The prominent objectives of the present study were to know the socio-economic profile of the workers and to know the awareness level of workers about the welfare measures. The descriptive research design was used and the data were collected with the help of a structured interview schedule. The sample size for this study is 200 workers of the sugar mills of Haryana. The data were analyzed and interpreted with the help of SPSS 21 . Themajor findings of the study were that majority of the respondents were males.And most of the respondents were educated up to $10^{\text {th }}$ to $12^{\text {th }}$. The awareness level of respondents indicates that the majority of the respondents were aware of the welfare measures.
\end{abstract}

Keywords: Labour, LabourWelfareMeasures, Awareness Level, Socioeconomic Status.

\section{Introduction}

The word "welfare" has many meanings such asgood health, happiness, well being, prosperity and betterment of human resources. the concept of well-being was a whole concept comprising the individual's mental, physical, moral, emotional and well-being. The social idea of welfare involves the welfare of people, their families 
and their communities. It is the interconnectivity of three things, in that they all work together and complement each other individually.

The concept of "welfare," as related to time and location, is considered a relative concept. Changes to the system affect the potential changes in welfare content, therefore, continue to fluctuate with time and space. The concept of welfare as a concept is also noted to vary throughout countries and places. Secondly, welfare is a positive concept because it would require certain minimal living conditions both in terms of biology and society if it were to set a minimum standard of life. Thus, when defined, the health, food, clothes, housing, care, insurance etc. components of the health care needs to be taken into account.The definition of work varies from one country to another, from one industry to another and from one location to another. Furthermore, it depends on the type of difficulty the company faces, modelled by age, sex, social-cultural background, economic standing and education of personnel in different businesses. The concept of use of the wellbeing of workers works as a motivational force for and for all workers.

\section{Significance of Labour Welfare}

Because of the fundamental structure of the industrial system, labour welfare has become crucial, and the approaches to this system varied between countries. Since our country continues to undergo the process of economic development, the terrible impacts of the industrial revolution which have harmed people all over the world are of some importance and slightly easier to combat. The Committee of the Royal Commission on Labor therefore strongly recognised the necessity for labour welfare as early as 1931, mainly in the interest of protecting every industrial worker from the hands of its employers. There are also some articles inserted in the directive principles of the Indian state. These articles are"Article 41 - The state shall within the limits of its economic capacity and development make effective provision for securing the right to work, to education and to public assistance in cases of unemployment, old age, sickness and disablement and in other cases of underserved want." And "Article 42 - The state shall make provision for securing just and humane conditions of work and for maternity relief." Another one is "Article 43 The state shall endeavour to secure, by suitable legislation or economic organisation or in any other way, to all workers, agricultural, industrial or otherwise work a living 
wage, conditions of work ensuring a decent standard of life and full enjoyment of leisure and social and cultural opportunities."

\section{Review of Literature}

Sriya, K., \& Krishna, P.M. (2014)conducted a study on "Status of Provision of the Factories Act-1948- A Study at Penna Cement Industries Limited (PCIL), Tadipatri'. The prominent objectives of the study were to examine the awareness levelof the workers regarding the welfare provisions under "The Factories Act1948 "in "Penna Cements, Tadipatri," to study the level of satisfaction regarding the welfare provisions of "The Factories Act-1948". In the research methodology chapter, the universe was all workers of "The Penna Cements, Tadipatri" and the sample size was 50 workers from the universe. Simple random sampling was used in this research study. Both types of data, primary and secondary were used.A structured interview schedule and questionnaire both were applied to collect the primary data. And; other various means were used to collect secondary data such as journals, web articles,books, magazines and information from the officials of the "Penna Cements, Tadipatri". It was found in the study that 43.0 per cent of the respondents were not aware of the welfare provisions and $57.0 \%$ of the respondents gave a neutral or poor awareness indication.

Tiwari, U. (2014)in her study "A Study on Welfare Facilities and Its Impact on Employees Efficiency at VindhaTelelinks Ltd. Rewa (M.P.),India" the main objectives for this research study were to know the various welfare amenities for the workers, to know the satisfaction level regarding different welfare measures, to propose the remedial actions to promote workers' well-being. In research methodology, a questionnaire was used consisting of 22 welfare components. The data were analyzed by using the five-point scale. It was found in the study that VTL Rewa(M.P.) was providing different sorts of amenities and following all the legal compliances of the State and Central government.

Prabakar, S. (2013)conducted a study on "Employees Satisfaction \& Welfare Measures: A Case Study With Special Reference to Don Bosco College of Arts \& Science, Sogathur, Dharmapuri" The leading objectives of this research study were to the awareness level regarding the welfare measures, to know the welfare practices that are prevailing in Don Bosco College, to know the socio-economic status of the 
respondents, to know the awareness level regardingthe welfare measures, to know employees welfare strategies in Don Bosco College, to know the socio-economic profile of the respondents, to maintain a healthy relationship between management and workers. In the present research study, the descriptive research design was used and the sample size was 80 workers. A questionnaire was applied to collect the primary data. And this questionnaire was given to each respondent to answer the questions. The leading outcomes of the present study were that all of the employees were involved in the trade union. $55.6 \%$ of the respondents were having more than 10 years of experience, $44.44 \%$ of the respondents were having 5-10 years of experience and there was not a single respondent who was having less than 5 years of experience. $33.33 \%$ of the respondents were coming under the below $5000 ₹$ category. $26.66 \%$ belonged to Rs.5000₹ $-10000 ₹$ and $40 \%$ belonged to above $10000 ₹$ categories.

Salaria, P., \&Salaria, S. (2013)conducted a study on "Employee Welfare Measures in Auto Sector". The main objectives of the study were to know about the workers' satisfaction level regarding the welfare measures, to know the impact of welfare amenities in maintaining healthy industrial relations, to know the welfare measures provided by the auto sector companies in NCR (National Capital Region), to know the awareness of welfare measures among the workers. In the research methodology chapter, a descriptive research design was used for the present research study. The universe of the study wasauto companies in NCR (National Capital Region). Total respondents were selected 50.Simple random sampling was used in this study and the researchers selected four auto companies randomly which were New Holland Fiat (India) Pvt. Ltd. HONDA SIEL, Yamaha, JCB. A questionnaire was applied to collect the primary data. Percentage analysis was used as a statistical tool. It was found in the study that the majority of the workers were satisfied in terms of welfare measures and a few were dissatisfied.

\section{Research Methodology}

In this research paper, the researcher has used a descriptive research design. For data collection, the researcher has applied a structured interview schedule to collect the data from the respondents. The sample size for the study is 200 workers of the sugar mills of Haryana. The data were analyzed and interpreted with the help of SPSS 21 . 


\section{Objectives:}

1. To know the socio-economic profile of the workers.

2. To know the awareness level of workers about the welfare measures.

Main Findings:

Table 1.1: Socio-Economic Status Of The Respondents

\begin{tabular}{|c|c|}
\hline Gender & Per cent \\
\hline Male & $96.5 \%$ \\
\hline Female & $3.5 \%$ \\
\hline Total & $100.0 \%$ \\
\hline Age & Per cent \\
\hline $20-25$ & $6.0 \%$ \\
\hline $25-30$ & $2.0 \%$ \\
\hline $30-35$ & $29.0 \%$ \\
\hline $35-40$ & $3.0 \%$ \\
\hline $40-45$ & $44.0 \%$ \\
\hline $45-50$ & $2.0 \%$ \\
\hline $50-55$ & $14.0 \%$ \\
\hline Total & $100.0 \%$ \\
\hline Education level & Per cent \\
\hline $10^{\text {th }}+$ ITI & $15.0 \%$ \\
\hline $12^{\text {th }}+\mathrm{ITI}$ & $16.0 \%$ \\
\hline Diploma & $9.5 \%$ \\
\hline Graduate & $1.0 \%$ \\
\hline Post-Graduate & $0.5 \%$ \\
\hline $10^{\text {th }}$ & $32.5 \%$ \\
\hline $12^{\text {th }}$ & $15.5 \%$ \\
\hline $8^{\text {th }}$ & $8.0 \%$ \\
\hline $5^{\text {th }}$ & $2.0 \%$ \\
\hline Total & $100.0 \%$ \\
\hline Monthly Income (in ₹) & Per cent \\
\hline ₹ 10,000 - ₹ 15,000 & $9.0 \%$ \\
\hline ₹ $15,001-₹ 20,000$ & $2.0 \%$ \\
\hline ₹ 20,001- ₹ 25,000 & $18.0 \%$ \\
\hline ₹ $25,001-₹ 30,000$ & $2.0 \%$ \\
\hline ₹ 30,001- ₹ 35,000 & $37.0 \%$ \\
\hline ₹ 35,001- ₹ 40,000 & $4.0 \%$ \\
\hline ₹ 40,001- ₹ 45,000 & $22.0 \%$ \\
\hline
\end{tabular}




\begin{tabular}{|l|l|}
\hline ₹ 45,001- ₹ 50,000 & $5.0 \%$ \\
\hline ₹ 50,001- ₹ 55,000 & $1.0 \%$ \\
\hline Total & $100.0 \%$ \\
\hline
\end{tabular}

Source: Primary DataN=200

Gender:The above-mentioned table 1.1reveals the distribution of respondents based on gender. Out of 200 respondents, 3.5 per cent were females and $96.5 \%$ were males. It was found in the study that the majority of the males were involved in employment. It was very strange to see that the femaleswere working in a very less number. It was because that it's a seasonal industry and the heavy work was to be done. So, industry management did not prefer to hire female employees in more numbers and even femalesdid not like to work in the sugar industry because of its seasonal nature. Because the outsourcing and contractual nature of the job were also one of the major reasons that femalesdid not come intothe sugar industry ona large scale.

Age:The above-mentioned table 1.1 explains the age of respondents. Out of the 200 respondents, 44.0 per cent were from 40-45 years of age group, followed by 29.0 per cent from 30-35 years, 14.0 per cent from 50-55 years of age group, 6.0 per cent from 20-25 years of age group, 3.0 per cent from the age group of 35-40, 2.0 per centfrom the age group of 45-50 and the remaining 2.0 per cent from the age group of 25-30 years of age group. It was found in the study that respondents belonged to different age groups. But 44.0 per cent of the respondents were from 40-45 years of age and they were working more than other age groups.

Education: The above-mentioned table 1.1 reveals the education qualifications of respondents. Out of the 200 respondents, 32.5 per cent were educated up to $10^{\text {th }}$, followed by 15.5 per cent educated up to $10+2$ th, 16.0per cent, educated up to $12^{\text {th }}+$ ITI, 15.0 per cent educated up to $10^{\text {th }}+$ ITI, 8.0 per centeducated up to $8^{\text {th }}$, only 9.5 per cent educated up to polytechnic diploma, 2.0 per cent were educated up to $5^{\text {th }}$ standard, 1.0 per cent educated up to graduation and the remaining 0.5 per cent educated up to the post-graduate.

Monthly Income:Table 1.1 reveals the income of respondents. In the table, it was found that 37.0 per centwere having the pay scale of ₹30001-35000, followed by 
22.0 per cent of the respondents were drawing the monthly salary ₹ 40001-45000, 18.0 per cent respondents werehaving the salary ₹ 20001-25000, 9.0 per cent of the respondents were receiving the salary ₹ 10000-15000,5.0per cent respondents were drawing the monthly salary at the scale of ₹ 45001-50000, 4.0 per cent of the respondents were receiving the salary ₹ 35001-40000, 2.0 per pent respondents were drawing the monthly income ₹15001-20000, 2.0per cent respondents were having the monthly salary ₹ 25001-30000 and lastly 1.0per cent of the respondents were receiving the monthly salary of ₹ 50001-55000.

\section{Awareness Level Among The Respondents Regarding The Labour Welfare}

\section{Measures}

This section deals with the awareness level of respondents regarding labour welfare measures provided in the sugar mills of Haryana.

Figure 1.1: Distribution of the responses given by the respondents regarding the subsidized food items in the factory's canteen.

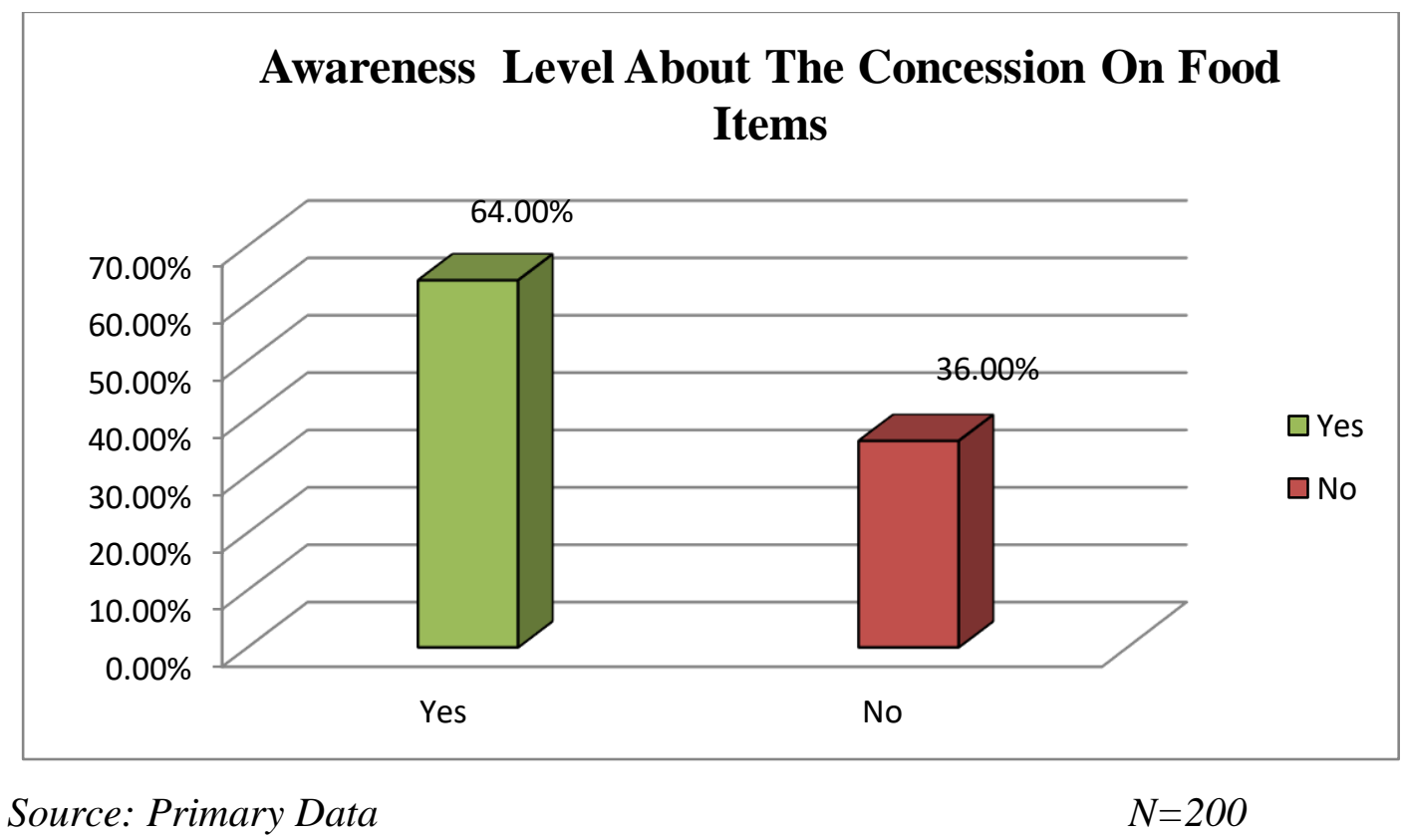

Figure 1.1represents the concessional rate of food items in the factory's canteen. Out of the 200 respondents, 64.0 per cent of the respondents told that the food items were provided at a concessional or nominal rate in the factory's canteen. On the contrary, 36.0 per cent of the respondents responded regarding this question that 
there was no concession on the food items in the factory's canteen. The market rate was beingappliedto the food items in the factory's canteen.

Figure 1.2: Distribution of the responses given by respondents regarding the appointment of labour welfare officer in order to do the welfare of workers.

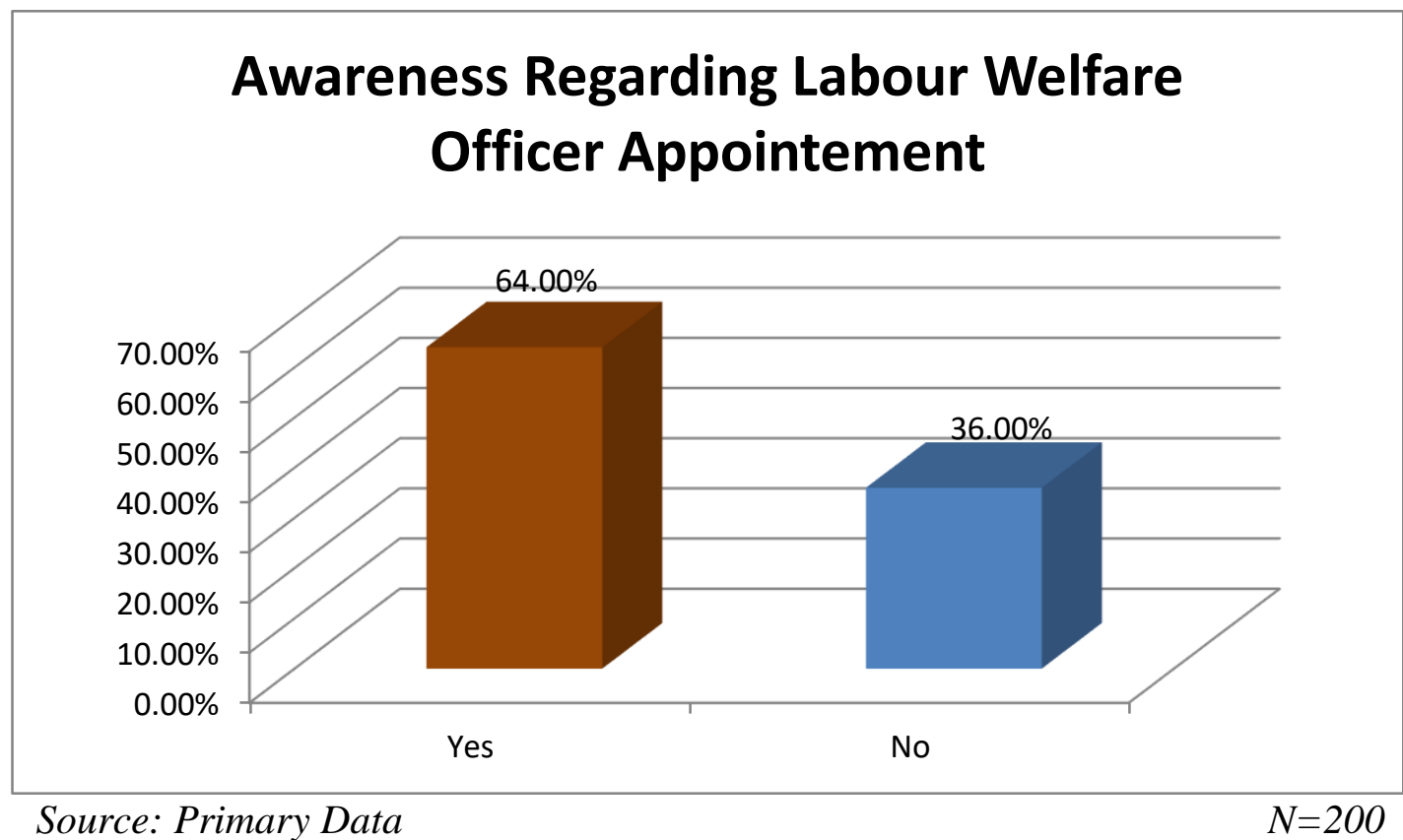

Figure 1.2 reveals the awareness level of respondents regarding the appointment of labour welfare for the well-being of the workers. Out of the200 respondents, 64.0 per cent of respondents replied that they knew that the appointment of a labour welfare officer is done for the welfare of workers. On the contrary, 36.0 per cent of the respondents answered that they did not know that the appointment of the labour welfare officer is done for the welfare of workers.

Figure 1.3: Distribution of responses given by the respondents regarding the organization of recreational activities at regular intervals for the workers. 


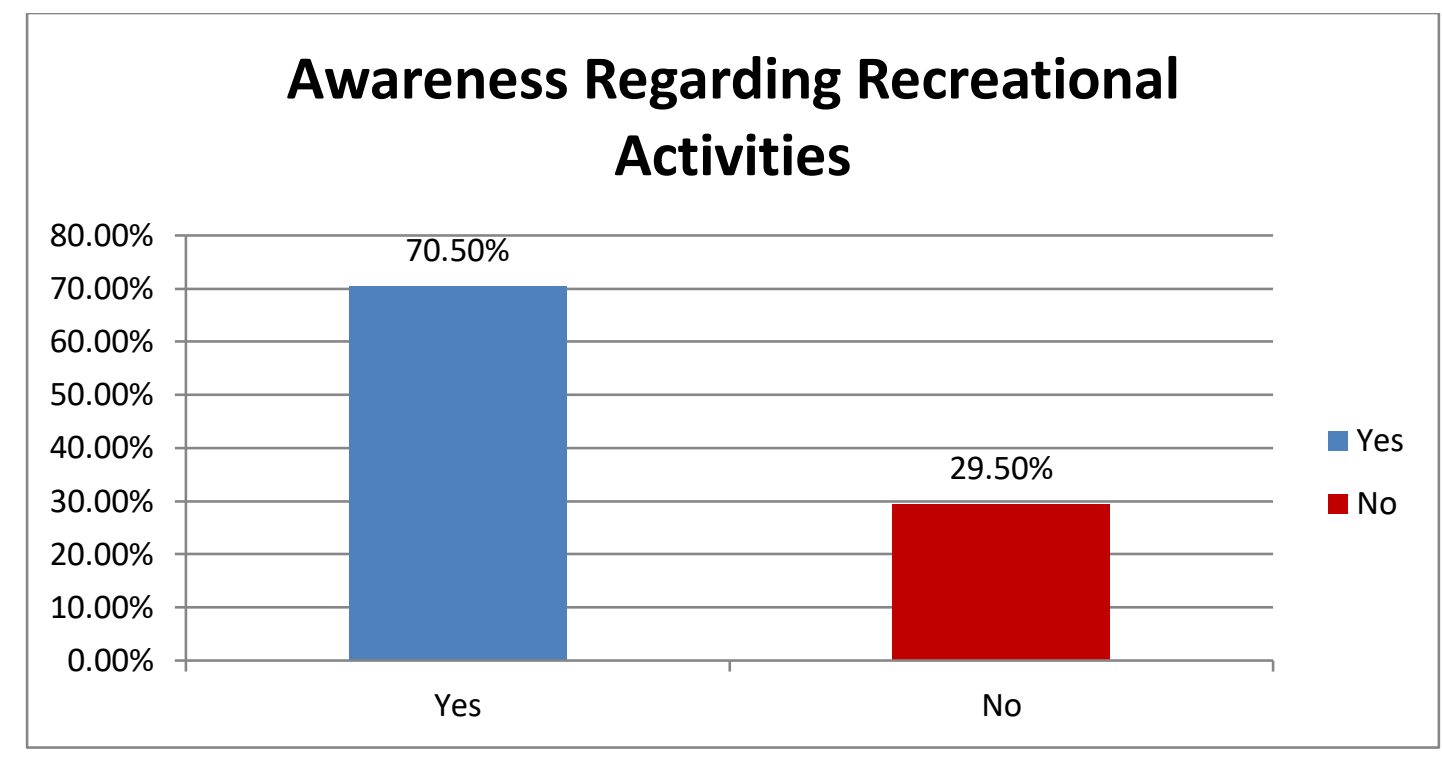

Source: Primary Data

$$
N=200
$$

Figure 1.3 reveals the awareness level of respondents regarding the organization of recreation activities at a regular interval. Out of the 200 respondents, 70.5 per cent of respondentsreplied that the recreational activities were organized at a regular interval. On the other hand, 29.5 per cent of the respondents answered that there was no organization of recreational activities.

\section{Conclusion}

Labour welfare measures play a vital role in the satisfaction of the employees of any industry. And without satisfying the labour no organization can effectively achieve its objective. So, to have the best potential in an organization, it is very much needed to provide labour welfare measures because labour welfare measures make the employees more dedicated and productive in terms of the organization and its management. Thus, labour welfare measures are the most important factor to keep the employees more dedicated and productive for the organization.

\section{Suggestions\& Recommedations}

1. The awareness level of workers regarding welfare measures is good but it can be improved.

2. Labour welfare officershave a vital role in improving the awareness level of the workers. 
3. The recreational activities can be made more interesting so that all workers can participate in these events.

4. Careful planning is required that can serve the objectives such as make the workers more participative in designing welfare policy.

5. It should be realized that extra amenities can build up a great sense of loyalty on the part of employees for their organization.

\section{References:}

file:///C:/Users//Desktop/Labour-Welfare-in-Indian-Perspective.pdf

http://www.jiwaji.edu/pdf/ecourse/political_science/MBA_HRD204_MEANING_T HEORIES_OF_LABOUR_WELFARE.pdf.

Parameshwaran, M., \&Shamina, M. H. (2014). Effectiveness OfLabour Welfare Measures In Cheyyar Sugar Mills-An Empirical Study. International Journal of Business and Administration Research Review, 3 (5), 129-134.

Prabakar, S. (2013). Employee Satisfaction \& Welfare Measures: A Case Study With Special Reference to Don Bosco College of Arts \& Science, Sogathur, Dharmapuri.Asia Pacific Journal of Research, 3 (10).

Salaria, P., \& Salaria, S. (2013). Employee welfare measures in the Auto sector. International Journal of Business and Management Invention, 66-74.

Sriya, K., \& Krishna, P. M. (2014). Status of Provisions of the Factories Act, 1948 A study at Penna Cement Industries Limited (PCIL), Tadipatri. IOSR Journal of Business and Management (IOSR-JBM), 16 (3), 14-26.

Tiwari, U. (2014). A Study on Employee Welfare Facilities and Its Impact on Employees Efficiency at Vindha Telelinks Ltd. Rewa (M.P.) India.Abhinav International Monthly Refereed Journal of Research in Management \& Technology, 3 (11), 1-7. 